\title{
The Effects of Alcohol on the H-reflex in Adults
}

\author{
Sung-Hyoun Cho, PT, MS ${ }^{1)}$, Eun-Jung Hong, PT, MS ${ }^{1)}$, Hwang-Bo KaK, PT, PhD ${ }^{2}$, \\ Tae-Young Moon PhD ${ }^{3)}$, Byung-Jun Cho, $\mathrm{PhD}^{3)}$ \\ 1) Major in Physical Therapy, Department of Rehabilitation Science, Graduate School of Daegu \\ University \\ 2) Department of Physical Therapy, College of Rehabilitation Science, Daegu University \\ 3) Department of Emergency Medical Technology, Kangwon National University: Kuydong Samcheok \\ City, Kangwondo, 245-711, South Korea.TEL: +82 33-570-6440,E-mail: cho6451@gmail.com
}

\begin{abstract}
Purpose] The purpose of this study was to compare the H-reflex in participants before and after alcohol intake. [Subjects] The aim of this study was to investigate the impact on the H-reflex after alcohol intake by performing experiments with adult subjects who were 19 to 27 years of age. Thirty subjects (men=15, women=15) were arranged into three groups. There were 10 people in each group. [Method] The three groups consumed $0.05 \mathrm{~mL} / \mathrm{kg}$, $0.4 \mathrm{~mL} / \mathrm{kg}$ and $0.8 \mathrm{~mL} / \mathrm{kg}$ of alcohol, respectively. An MP150 (BIOPAC Systems, Inc., Goleta, CA, USA) was used to obtain the values measured by electromyography $(\mathrm{EMG})$ using $\mathrm{Ag}-\mathrm{Ag} / \mathrm{Cl}$ measurement electrodes (BIOPAC, diameter of $2 \mathrm{~cm}$ ). Waves were measured to assess the action potential of the central neuron. [Results] In Group I, the H-reflex was 4\% lower after 6 hours compared with before alcohol intake. In Group II, it was 10\% lower after 6 hours compared with before alcohol intake. In Group III, it was 31\% lower after 6 hours compared with before alcohol intake. H-reflex was mostly decreased in the three groups after alcohol intake. [Conclusion] Drinking may cause problems with ADL. The results also show that having alcohol before work that requires intensive concentration would cause more accidents and injuries, as alcohol affects the human H-reflex. The amount of alcohol intake was found to have an influence on the H-reflex.

Key words: Alcohol, H-reflex, Recovery
\end{abstract}

(This article was submitted May 11, 2012, and was accepted Jun. 20, 2012)

\section{INTRODUCTION}

It was reported that the amount of alcohol consumption has been increasing in daily life; the drinking ratio in adults over 20 years of age was reported to be around $76.4 \%$; Koreans were ranked No. 2 in the world in regard to the amount of alcohol intake according to the WHO, consuming 14.4 liters per year ${ }^{1}$. In regard to the drinking rates of Korean college students, $95.2 \%$ of male students and over $90.0 \%$ of female students drink, showing high rates of drinking in these groups, and in particular, female students displayed a higher rate than normal women, which is a matter of concern ${ }^{2}$.

Alcohol is reported to have an effect on the central nervous system, and to reduce the role of neurotransmitter systems. These include adenosine, glycine, acetylcholine, monoamine and neuropeptide ${ }^{3-6}$. Alcohol also has a critical influence on the membrane, voltage-gated ion channel and the second messenger system ${ }^{6}$. In the neurotransmitter system, two essential amino acids, $\gamma$-aminobutyric acid (GABA) and excitant amino acid (EAA), receive a great deal of attention. To be more specific, alcohol increases inhibitory neurotransmission, decreases excitatory neurotransmission, or acts as an inhibitor by a combination of these $^{7}$. Consumption of too much alcohol causes proteincalorie malnutrition and a shortage of micronutrients, such as folic acid, vitamin A, vitamin B1, vitamin B6, vitamin
B12, magnesium, potassium, and zinc, consequently causing chronic pancreatopathy, cardiac disorders, alcoholic cirrhosis, alcoholic myopathy, stroke, various skin diseases, and several cancers ${ }^{8-10)}$. However, the alcohol issue is no longer limited to diseases; it compounds social problems, which creates individual physical and mental problems, family problems like domestic violence and child abuse, social problems including drunk driving, delinquency and crimes, loss of productivity, and increases in medical expenses and social costs ${ }^{11)}$.

Objective and quantitative evaluation is indispensable for evaluating functional loss or treatment result, predicting prognosis, and so forth. An electrodiagnostic method utilizing H-reflection is used for quantitative evaluation. The Hoffmann's reflex (H-reflex) is a monosynaptic and neuromuscular response that was first reported by Hoffmann in 1919 and generally occurs when a percutaneous electrical stimulus is applied to a peripheral nerve that is a mixed nerve ${ }^{12)}$. With respect to the H-reflex, when a tibial nerve is stimulated with a lower stimulus than the maximum stimulus, the initial action potential and late action potential can be seen in the gastrocnemius, in which the former is called the $\mathrm{M}$ wave and the latter is called the $\mathrm{H}$ wave. The H-reflex is a reflected wave through which an afferent fiber passes through the Ia nerve fiber (a sensory nerve), enters the posterior horn of the spinal cord, passes through the 
Table 1. Characteristics of the subjects

\begin{tabular}{lcccc}
\hline Items & $\mathrm{N}$ & Age $(\mathrm{y} / \mathrm{o})$ & Height $(\mathrm{cm})$ & Weight $(\mathrm{kg})$ \\
\hline Experimental group I & 10 & $23.1 \pm 2.3$ & $167.9 \pm 13.1$ & $63.7 \pm 7.5$ \\
Experimental group II & 10 & $20.4 \pm 1.6$ & $169.1 \pm 9.1$ & $58.6 \pm 7.7$ \\
Experimental group III & 10 & $22.1 \pm 2.8$ & $165.7 \pm 9.6$ & $63.1 \pm 5.3$ \\
\hline Note. Values are means \pm SD. * Significantly different $(\mathrm{p}<0.05)$, Experimental group I $: 0.05$ \\
$\mathrm{~mL} / \mathrm{kg}$ alcohol group, Experimental group II $: 0.4 \mathrm{~mL} / \mathrm{kg}$ alcohol group, Experimental group \\
III : $0.8 \mathrm{~mL} / \mathrm{kg}$ alcohol group
\end{tabular}

monosynaptic reflex arch, and comes around by the A-alpha nerve fiber (a motor nerve $)^{13-15)}$. In childhood, it is recorded in all the muscles, but in adulthood, an electrostimulus that produces the H-reflex is normally under the control of sacral vertebra No.1 and moves forward in efferent fiber through the motor neuron pool of the muscle that connects to a sensory fiber, so the effectiveness of synaptic conduction can be measured via the H-reflex ${ }^{12}$. The H-reflex is regarded as a monosynaptic reflex involved in both peripheral sense and a motor fiber. After injecting a small amount of alcohol, an important difference in balance was proved ${ }^{16)}$. Major precedent studies of alcohol were led by a study on the state of nutritional intake, eyesight, and blood components after drinking. However, there has been no study that has evaluated the relation between alcohol and the effectiveness of synaptic conduction in neurons. This study focusses on the correlation between alcohol and the excitability of neural action potential. Therefore, it investigates the efficiency of synaptic conduction through the H-reflex, which can identify differences in groups according to alcohol intake and the difference in time processing, and the effect on the human body.

\section{SUBJECTS AND METHODS}

\section{Subjects}

The number of subjects was 30 (15 men and 15 women), and subjects (5 men and 5 women) were assigned to each of three groups. The participants were not informed about the specific processes, and alcohol intake was applied differently in each of the groups, which were divided according to the amount of alcohol intake as follows: $0.05 \mathrm{~mL} / \mathrm{kg}, 0.4 \mathrm{~mL} / \mathrm{kg}$, and $0.8 \mathrm{~mL} / \mathrm{kg}$ (Table 1). All of the subjects fully understood the test contents and voluntarily participated in the test. They filled out a translated version of an English language consent form from a children's hospital in Los Angeles, CA, USA. The subjects of the study were all normal adults and were chosen by the following standard:

1. Persons with no alcohol intake 3 days before test and with an empty stomach for 4 hours before the test.

2. Persons with no alcohol or drug addiction, no specific reaction, and nothing significant to psychologically report.

3. Persons with no chronic diseases, such as deteriorative or active disorders, hypertension, diabetes, hepatitis, and renal insufficiency.

4. Persons using no other drugs that can affect alcohol intake or metabolism.

\section{Methods and Procedure}

This study designed the following tests in order to investigate excitability of the central neuron action potential, and compare the difference between groups and the difference in time processing according to alcohol intake. The subjects were tested at the following time points: before alcohol intake, immediately after intake, 2 hours later, 4 hours later, and 6 hours later.

An MP150 (BIOPAC Systems, Inc., Goleta, CA, USA) was used to obtain the values measured by electromyography using $\mathrm{Ag}-\mathrm{Ag} / \mathrm{Cl}$ measurement electrodes (BIOPAC, diameter of $2 \mathrm{~cm}$ ). The signal from electromyography was collected at a sampling rate of $1000 \mathrm{~Hz}$ and processed with full-wave rectification. To save data, the AcqKnowledge 4.1 (BIOPAC Systems, Inc., Goleta, CA, USA) software was used; band-pass filtering at $30-500 \mathrm{~Hz}$, notch filtering at $60 \mathrm{~Hz}$, and signal processing were performed with this software. The measured data were converted into root mean square, RMS, values and analyzed based on the average values of three measurements.

The $\mathrm{H}$ wave was used to evaluate the action potential of the central nervous system. The subjects were told to lie on their stomachs, and their ankles were put ahead of the bed and positioned in a central location. To measure the $\mathrm{H}$ wave, the skin was sanitized with $70 \%$ alcohol and dried to remove moisture, and electrodes were applied to the skin. The recording electrode was applied to a central point that divided strings connecting the center of the folds of the popliteal fossa and the proximal site nearest to the medial malleolus; the reference electrode was put on the Achilles tendon; and the ground electrode was placed on the external gastrocnemius muscle, which was $3 \mathrm{~cm}$ above the active electrode. A $1 \times 1 \mathrm{~cm}$-sized self-adhesive disposable electrode (Neuroline Disposable neurology electrodes 700 10-k, Medicotest A/S, Olstykke, Denmark) was used as the ground electrode. An electrostimulus was applied for 2 seconds at the submaximal stimulation level on the center folds of the popliteal fossa of the posterior tibial nerve by using a dual electrode.

We used SPSS version 12.0 (ICC, Chicago, IL, USA) for data analysis. Descriptive statistics are reported as means \pm standard deviation $(\mathrm{M} \pm \mathrm{SD})$. A one-way analysis of variance (ANOVA) was used to determine the difference between the groups. We used repeated measure analysis of variance to verify the mean difference in time variation (pretest, posttest, and 2, 4, and 6 hours after the intake of alcohol) within each group. Statistical significance was set at $\mathrm{p}<0.05$ for all analyses. 
Table 2. H-reflex change, interaction between time and groups

\begin{tabular}{cccccc}
\hline Group & Rest & Immediate & 2 hours (y/o) & 4 hours & 6 hours \\
\hline I & $4.07 \pm 0.67$ & $3.78 \pm 0.72$ & $3.70 \pm 0.24$ & $3.79 \pm 0.75$ & $3.90 \pm 0.67$ \\
II & $4.54 \pm 0.97$ & $3.70 \pm 0.95$ & $3.35 \pm 0.74$ & $4.02 \pm 0.80$ & $4.10 \pm 1.36$ \\
III & $4.79 \pm 2.13$ & $3.47 \pm 1.98$ & $2.90 \pm 1.85$ & $3.11 \pm 1.77$ & $3.33 \pm 1.71$ \\
\hline
\end{tabular}

\section{RESULTS}

In the results of the repeated measures ANOVA for the H-reflex change, the interaction between time and group showed a significant difference $(\mathrm{p}<0.05)$, indicating that there was a significant difference in the change in H-reflex by time between the groups. In Group I, the value dropped from $4.07 \pm 0.67$ to $3.78 \pm 0.72$ immediately after alcohol intake and subsequently decreased to $3.70 \pm 0.24$ after 2 hours. After 4 hours, the value increased to $3.79 \pm 0.75$, and it was $3.90 \pm 0.67$ after 6 hours. In Group II, the value decreased from $4.54 \pm 0.97$ to $3.70 \pm 0.95$ immediately after alcohol intake and increased to $4.36 \pm 1.36$ after 6 hours. In Group III, the value decreased from $4.79 \pm 2.13$ to $3.47 \pm 1.98$ immediately after alcohol intake and subsequently decreased to $2.90 \pm 1.85$ after 2 hours. It then increased to $3.11 \pm 1.77$ after 4 hours and to $3.33 \pm 1.71$ after 6 hours (Table 2).

\section{DISCUSSION}

A large quantity of alcohol causes problems with nutrient digestion, absorption, and metabolism, reduces meal size, and changes eating habits, leading to innutrition, and acetaldehyde, which is an intermediary metabolism material, is produced through the oxidation process of alcohol, triggers cell damages, and affects some organs in the body, leading a change in physiological function and a variety of metabolic disorders ${ }^{17}$. Alcohol is a nonspecific restrainer of the central nervous system, and its suppressive effect is particularly seen in the reticular formation and cerebral cortex, but it is seen in all central nervous systems including the brain stem and cerebellum, and its relevant neurotransmitter is dopamine ${ }^{18)}$. Dopamine acts as an excitatory neurotransmitter in the nervous system action, GABA acts as an inhibitory neurotransmitter, and the GABA receptor contains direct inhibition ${ }^{19)}$. In regard to other alcoholic effects, firstly, it causes unbalance in static balance control in general, in integrated posture in particular, and voluntary actions, and secondly, it induces disorders by increased incompetence ${ }^{20)}$. The aim of this study was to investigate the difference in effect on synaptic conduction through the H-reflex after applying alcohol, a restrainer of the central nervous system, to the body. The H-reflex can be obtained by applying a light-strength electrostimulus to mixed peripheral nerves that have a sensory nerve fiber and a motor nerve fiber. The characteristics of the H-reflex were used to verify the effect on nerves through electrostimulus treatment ${ }^{21,22)}$. Moreover, a study to investigate the change in excitability in regard to the spinal neuron based on artificial sensory input has been conducted together with a study on the change in the H-reflex by applying artificial sensory input to the pelvic $\operatorname{limb}^{23}$. In the results of the analysis with repeated measures ANOVA for the H-reflex change in order to measure the effectiveness of synaptic conduction after application of alcohol, the interaction between time and groups showed a significant difference $(\mathrm{p}<0.05)$, indicating that there was a significant difference in the change in H-reflex by time between the groups. In Group I, it decreased by $8 \%$ immediately after alcohol intake, and after 6 hours, it was 4\% lower compared with before alcohol intake, presenting a significant difference by time. In Group II, it showed the decrease of $19 \%$ immediately after alcohol intake, and after 6 hours, it was $10 \%$ lower compared with before alcohol intake. In Group III, it displayed a 28\% drop immediately after alcohol intake, and after 6 hours, it was 31\% lower compared with before alcohol intake. In this study, the amount of alcohol consumed in each group resulted in significant differences in groups by time, and the delay in recovery of the H-reflex as the amount of alcohol increased. In this way, the H-reflex is a monosynaptic reflex that can be used to evaluate the functional condition of a reflex loop at the spinal cord level. It has been used to utilized to test excitability at the level of the spinal cord level, and in particular, it could be investigated in connection with various types of disease conditions that hinder the excitability of spinal cord motion.

\section{REFERENCES}

1) The Korean nutrition society: Dietary references intake for Koreans (1st ed). Seoul: Hanareum, 2010, pp 1-9.

2) Lee WJ: Factors related to college student's problem drinking. J Kor Soci Health Educ Promo, 2003, 20: 109-124.

3) Lau AH, Frye GD: Acute and chronic actions of ethanol on CA1 hippocampal responses to serotonin. Brain Res, 1996, 731: 12-20. [Medline] [CrossRef]

4) Mascia MP, Machu TK, Harris RA: Enhancement of homomeric glycine receptor function by long-chain alcohols and anaesthetics. Br J Pharmacol, 1996, 119: 1331-1336. [Medline] [CrossRef]

5) Wang Y, Jeng $\mathrm{CH}$, Lin JC, et al.: Serotonin modulates ethanol-induced depression in cerebellar purkinje neurons. Alcohol Clin Exp Res, 1996, 20: 1229-1236. [Medline] [CrossRef]

6) Mullikin-Kilpatrick D, Treistman SN: Voltage-gated calcium channels. In: Pharmacological effects of ethanol on the Nervous System. Boca Raton: CRC Press, 1996, pp 29-49.

7) Valenzuela CF: Alcohol and neurotransmitter interactions. Alcohol Health Res World, 1997, 21: 144-148. [Medline]

8) Tjønneland A, Christensen J, Thomsen BL, et al.: Lifetime alcohol consumption and postmenopausal breast cancer rate in Denmark: A prospective cohort study. J Nutr, 2004, 134: 173-178. [Medline]

9) Bagnardi V, Blangiardo M, Vecchia CL, et al.: Alcohol consumption and the risk of cancer: A meta-analysis. Alcohol Res Health, 2001, 25: 263-270. [Medline]

10) Halsted CH, Villanueva JA, Devlin AM, et al.: Metabolic interactions of alcohol and folate. J Nutr, 2002, 132: 2367S-2372S. [Medline]

11) Kwon TY, Kahng SK: The effects of alcohol-use factors and psychological factors on spouse abuse. Kor J Fam Soc Work, 2007, 20: 223-258.

12) Palmieri RM, Ingersoll $\mathrm{CD}$, Hoffman MA: The Hoffmann Reflex: 
Methodologic considerations and applications for use in sports medicine and athletic training research. J Athl Train, 2004, 39: 268-277. [Medline]

13) Dumitru D.: Amato AA, Zwarts M: Electrodiagnostic medicine (2nd ed) Philadelphia: Hanley \& Belfus, 2002, pp 244-251.

14) Hoffman P: Uber die Beziehumger der Sehnen reflex zur wilkurjichen bewegung und zum tonus. Z Biol, 1918, 68: 351-370.

15) Hoffman MA, Koceja DM: The effects of vision and task complexity on Hoffman reflex gain. Brain Res, 1995, 700: 303-307. [Medline] [CrossRef]

16) Mangold S, Läubli T, Krueger H: Effects of a low alcohol dose on static balance, fine motor activity, and mental performance. Neurotoxicol Teratol, 1996, 18: 547-554. [Medline] [CrossRef]

17) Lee EH, Chyun JH: Effect of carotene supplementation in lipid peroxide levels and antioxidative enzyme activities in alcoholic fatty liver rats. Kor J Nutr, 2005, 38: 289-296.

18) Na DR, Lee JB, Im CS: The Effects of alcohol on eye movement. Kor J
Ophthalmol Soc, 2000, 41: 215-224.

19) Costa ET, Savage DD, Valenzuela CF: A review of the effects of prenatal or early postnatal ethanol exposure on brain ligand-gated ion channels. Alcohol Clin Exp Res, 2000, 24: 706-715. [Medline] [CrossRef]

20) Woollacott MH: Effects of ethanol on postual adjustments in humans. Exp Neurol, 1983, 80: 55-68. [Medline] [CrossRef]

21) Roh JR: Inter-examiner variability of H-reflex changes by transcutaneous electrical nerve stimulation. Unpublished master's thesis, Kosin University, Busan, 2006, pp 1-10.

22) Ginanneschi F, Dominci F, Milani P, et al.: Changes in the recruitment curve of the soleus H-reflex associated with chronic low back pain. Clin Neurophysiol, 2007, 118: 111-118. [Medline] [CrossRef]

23) Kennedy PM, Inglis JT: Modulation of the soleus H-reflex in prone human subfects using galvanic vestibular stimulation. Clin Neurophysiol, 2001, 112: 2159-2163. [Medline] [CrossRef] 